\title{
A hospital based prospective survey of perinatal depression in Chinese women of Jiamusi city
}

\author{
Palikhe Bishnu', Tong Li Bo"', Khatri Kalu Singh², Pariyar Jewan', Song Shi Qun', Piao Ying Lan', He Jian' and Xing Tian Rong' \\ *Correspondence: lockandkey2016@hotmail.com

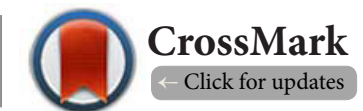

'Department of Obstetrics and Gynecology, First Affiliated Hospital of Jiamusi University, Heilongjiang, China.

2Department of Oral and Maxillofacial Surgery, National Academic of Medical Sciences, Nepal.

\begin{abstract}
Objectives: To evaluate whether an antenatal and immediate postpartum Edinburgh Postnatal Depression Scale score are predictive of future postpartum depression and observe the correlation in-between the scores and associated risk factors.

Methods: Study Design A survey recruiting 345 women from March 2015 to February 2016 using Edinburgh Postnatal Depression Scale for same group of individuals: once before the delivery, during third trimester and twice postpartum in women seeking antenatal service in three major hospital of Jiamusi, Heilongjiang Province, China. We used cut-off score $<12$ as normal and $>13$ as risk of depression. The relation between EPDS scores across three stages were assessed using Spearman's correlation, chi-square test was used to examine association of socio-demographic variable and series of logistic regression to examine statistical significance between EPDS scores and associated risk factors.

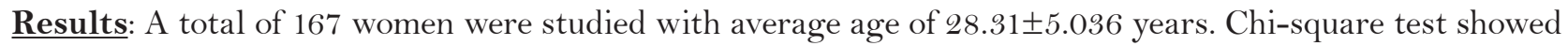
that younger $(p=0.029)$, unemployed $(p=0.022)$, primiparous $(p=0.039)$, less educated $(p=0.040)$ women are more prone to perinatal depression. Further Spearman's Non-parametric correlation test showed that postpartum depression has positive correlation with both antepartum $\left(\chi^{2}=3.977, \mathrm{df}=1, \mathrm{p}=0.018\right)$ and immediate postpartum $\left(\chi^{2}=3.977, \mathrm{df}=1, \mathrm{p}=0.046\right)$. Binary logistic regression analysis showed that parity (Wald=4.754, $\mathrm{p}=0.029$ ), and occupation (Wald=3.839, $\mathrm{p}=0.050$ ) were independent risk factors for antepartum depression. Mode of birth (Wald=4.513, $\mathrm{p}=0.034$ ), antepartum EPDS score (Wald=3.877, $\mathrm{p}=0.049$ ) and immediate postpartum EPDS score (Wald $=4.038, \mathrm{p}=0.044$ ) were independent risk factors for postpartum depression.

Conclusions: 1) Higher EPDS score prenatally tends to persist postnatal indicating chances of developing postpartum depression in susceptible individuals.

2) Early screening prenatally can guide clinician for active psychological support to susceptible cases thereby minimizing probability of postpartum depressions.
\end{abstract}

Keywords: Antenatal, edinburgh postnatal depression scale, perinatal depression, postnatal

\section{Introduction}

Depression is the leading cause of disability worldwide which is more common in women than in men and especially during reproductive age [1,2]. According to World Health Report 2001, depression is fourth in context of global burden of disease [3]. Perinatal depression (PND) is the depression which occurs during pregnancy or within few months after delivery. Prevalence of depression during pregnancy is about $10 \%$ and during postpartum period is about 13\% [4]. PND usually presents with symptoms like depressed mood, anxiety, fatigue, feeling of guilt, negative thoughts of injuring oneself and to the child as well, loss of concentration, loss of sleep. These symptoms often goes unrecognized which may be attributed to normal pregnancy changes. Perinatal depression affect mother as well as children and relationships also. Despite this impact, depression is perhaps one of the most effectively treated psychiatric 
disorder if recognized and treated early. Most women with depression in the perinatal period do not receive adequate care and support from family. Researches have adverted that women with antenatal depression are more prone to postpartum depression which when identified earlier enables healthcare professionals to follow up high risk women and apply preventive measures to prevent PND [5].

Routine screening for depression to identify patients with unrecognized depression with self-report questionnaire cements[grammar] mother-child relationship and has positive effect on health and well-being of the infant and family. The American College of Obstetricians and Gynecologists and the U.S. Preventive Services Task Force recently recommended universal perinatal depression screening [6]. As prevention of perinatal depression is not reliable, early detection is the best approach. Several screening tools have been validated to measure the depressive disorders like Edinburg Postnatal Depression Scale(EPDS), Postpartum Depression Screening Scale, Beck Depression Inventory etc. Routine screening of perinatal depression has been implemented in several countries [7]. Although routine screening is important for perinatal depression, it must be coupled with appropriate follow up and treatment if needed.

It is important to find the association between antenatal and postnatal depressive symptoms during pregnancy. Use of different measuring tools [8-10], various cut-off points $[5,11]$, and inconsistent screening procedure [5] prevent the direct comparison between the studies. Here, we used EPDS for screening perinatal depression as it is validated tool for antepartum and postpartum depression screening. It generally takes 5 minutes to complete depending upon level of literacy of women.

\section{Aim and objectives of this study}

1. To assess whether an antenatal and immediate postpartum EPDS score are predictive of future postpartum depression.

2. To analyze whether age, parity, occupation, education, marital status, history of abortion, history of chronic illness have any association with perinatal depression or not.

3. To describe patterns of change in EPDS score during the course of events, through which we can observe the correlation in-between them.

\section{Materials and methods Design}

This was a longitudinal survey which involves repeated measure at three different point of time for same group of individuals: once before the delivery during third trimester and twice postpartum ( 3 days after delivery and 1 month after delivery). The purposes of this survey is: to describe patterns of change during the course of events, through which we can observe the correlation in-between them [12]. The target population was Chinese women in Jiamusi Municipal area of Heilongjiang Province China.

\section{Sample collection}

All pregnant women in third trimester from March 2015 to February 2016 willing to participate in the study attending antenatal clinic or admitted to obstetric department of three major hospital (First affiliated hospital of Jiamusi University, Central Hospital of Jiamusi and Maternal and Child Health hospital of Jiamusi) were included in the study and their informed written consent was obtained. Family members of women with elevated EPDS scores, those suspicious of future PND were educated about its consequences and suggested for extra-care and support.

\section{Eligibility criteria}

1) Aged 18 years and older

2) Able to speak, read and write Chinese

3) Able to cooperate with data collection methods

\section{Exclusion criteria}

1) Women who are already being treated for depression

2) Limited ability to speak, read and write Chinese

3) Those under 18 years of age

\section{Measurement}

The self-administered questionnaire focusing on socio-demographics and known psychosocial risk factors for perinatal depression with Chinese version of EPDS [13] was used to collect data. EPDS [14] is a 10 item questionnaire developed to screen for depression in peripartum period because it has been validated for antenatal [15] and postnatal periods [16]. Each question is scored on a scale of 0-3 and total EPDS score of the individual is obtained by adding up scores of each questions. On the basis of the ease of integration of a busy obstetrics practice screening times for the study were chosen. From the EPDS score measured through different three stages two groups were created those $\leq 12$ and those $\geq 13$ in each stage. As majority of the researches have stated cut off score of $\leq 12$ and $\geq 13$ to be highly sensitive and specific, for this study purpose too patients with $\leq 12$ score were considered as non-depressed and patients with $\geq 13$ were considered to be depressed [14,17-19].

\section{Data analysis}

The SPSS 21.0 statistical software package was used for the statistical analysis. Descriptive Statistics (including means, standard deviations, frequencies and percentage) were calculated for the socio-demographic and obstetrics data. Chi square test was applied for association of perinatal depression with different variables. A reliability test was carried out for the EPDS in the three stages. Spearman's product correlation were used to examine the relationships among EPDS scores. The level of significance was set throughout the study at $p \leq 0.05$. A repeated measure of analysis was used to analyze the changes of EPDS scores across three stages. We conducted series of logistic regression to examine whether the statistically sig- 
nificant association between EPDS scores are attenuated by age, parity, abortion history, education level, occupational status, history of chronic illness, mode of conception, mode of birth, mode of feeding, pregnancy complication.

\section{Results}

A total of 345 women were invited to take part in the study, $292(84.64 \%)$ completed the questionnaire in first time assessment. Fifty-three women (15.36\%) refused to take part due to the lack of time and/or hesitation to give information. Patients were assessed postpartum three days after delivery for second assessment where, $228(81.45 \%)$ patients respond to the questionnaire. During third assessment one month after delivery, 167 women (82.32\%) responded to telephone call and finally 167 women participated in all three point of time for the study and were included in the analysis.

The average age of participants was $28.31 \pm 5.036$ years with range of 18-42 years. Higher number of participants had acquired high school level education (50.3\%) similarly university level (44.3\%) and primary school level (5.4\%). More than half of participants (55.7\%) were unemployed and $44.3 \%$ of participants were employed. Primiparous compromise $76 \%$ of study and $24 \%$ were multiparous. $38.9 \%$ of participant had previous history of abortion. The abortion rate are more common and high in China [20]. 9.6\% of participant had previous of chronic illness like diabetes, hypertension, heart diseases and others. 9.6\% of women were had undergone through artificial reproductive technique on recent pregnancy. Majority of women gave birth by caesarean method (92.2\%) and $7.8 \%$ by normal vaginal delivery. Majority of women were exclusively breast feeding $81.4 \%(n=136)$ and $18.6 \%(n=31)$ of women did not breastfed. Medical and obstetrical complication were found in $11.4 \%$ of women from recent pregnancy like gestational diabetes, hypertension, heart disease, anemia or other complication. Table 1 summarize Socio-demographic variables of the cases recruited in the study.

According to score all socio-demographic data and clinical data were classed into two categories (Figure 1) to check the correlation between them and comparison of EPDS scores across three stages were done. Cross tabulation was done between EPDS scores. Bivariate analysis using chi-square test was employed to check potential correlation between each socio-demographic data with EPDS and each EPDS score with subsequent EPDS scores and/or associated obstetrical complications. Chi-square test showed that younger $\left(X^{2}=4.786\right.$, $\mathrm{df}=1, \mathrm{p}=0.029)$, unemployed $\left(\mathrm{x}^{2}=5.282, \mathrm{df}=1, \mathrm{p}=0.022\right)$, primiparous $\left(x^{2}=4.258, d f=1, p=0.039\right)$, less educated $\left(x^{2}=4.215\right.$, $\mathrm{df}=1, \mathrm{p}=0.040$ ) women are more prone to perinatal depression (Table 2).

Further Spearman's Non-parametric correlation test was done to check correlations between initial and subsequent EPDS scores. EPDS 3 has positive correlation with both EPDS 1 and EPDS 2 but the correlation of EPDS 3 with EPDS $1\left(x^{2}=3.977\right.$, $\mathrm{df}=1, \mathrm{p}=0.018)$ is stronger compared with EPDS $2\left(x^{2}=3.977\right.$,
Table 1. Social demographic characteristics.

\begin{tabular}{|c|c|c|c|}
\hline Variables & Categories & Number & Percentage \\
\hline \multirow{2}{*}{ Parity } & Primiparous & 127 & 76 \\
\hline & Multiparous & 40 & 24 \\
\hline \multirow[t]{3}{*}{ Education level } & $\begin{array}{l}\text { Primary school level } \\
\text { obtained }\end{array}$ & 9 & 5.4 \\
\hline & High school/college & 84 & 50.3 \\
\hline & University & 74 & 44.3 \\
\hline \multirow{5}{*}{$\begin{array}{l}\text { Occupational } \\
\text { status }\end{array}$} & Student/ housewife & 85 & 50.9 \\
\hline & Private business & 10 & 6 \\
\hline & Employed & 55 & 32.9 \\
\hline & Unemployed & 8 & 4.8 \\
\hline & Others ${ }^{\star}$ & 9 & 5.4 \\
\hline \multirow{6}{*}{$\begin{array}{l}\text { Previous H/0 } \\
\text { chronic diseases }\end{array}$} & No any & 151 & 90.4 \\
\hline & Heart diseases & 2 & 1.2 \\
\hline & Drug allergy & 9 & 5.4 \\
\hline & Diabetes with hyper- & 1 & 0.6 \\
\hline & tension & 4 & 2.4 \\
\hline & Others* & -- & -- \\
\hline \multirow{2}{*}{$\begin{array}{l}\text { Previous H/O } \\
\text { abortion }\end{array}$} & No H/O abortion & 102 & 61.1 \\
\hline & Previous H/O abortion & 65 & 38.9 \\
\hline \multirow{2}{*}{$\begin{array}{l}\text { Mode of } \\
\text { conception }\end{array}$} & Natural process & 151 & 90.4 \\
\hline & $\begin{array}{l}\text { Artificial reproductive } \\
\text { technique }\end{array}$ & 16 & 9.6 \\
\hline \multirow[t]{2}{*}{ Mode of feeding } & Breast feeding & 136 & 81.4 \\
\hline & Bottle feeding & 31 & 18.6 \\
\hline \multirow[t]{2}{*}{ Mode of birth } & $\begin{array}{l}\text { Normal vaginal } \\
\text { delivery }\end{array}$ & 13 & 7.8 \\
\hline & Cesarean delivery & 154 & 92.2 \\
\hline \multirow[t]{2}{*}{ Complication } & No any & 148 & 88.6 \\
\hline & $\begin{array}{l}\text { Hypertension/heart } \\
\text { diseases/diabetes }\end{array}$ & 19 & 11.4 \\
\hline \multirow[t]{2}{*}{ Age } & $<25$ & 58 & 34.7 \\
\hline & $\begin{array}{l}>25 \\
\mathrm{M} \pm \mathrm{SD}=28.31 \pm 5.036 \\
\text { Range }=18-42 \text { years }\end{array}$ & 109 & 65.3 \\
\hline
\end{tabular}

${ }^{*}$ not specified, sample number is 167

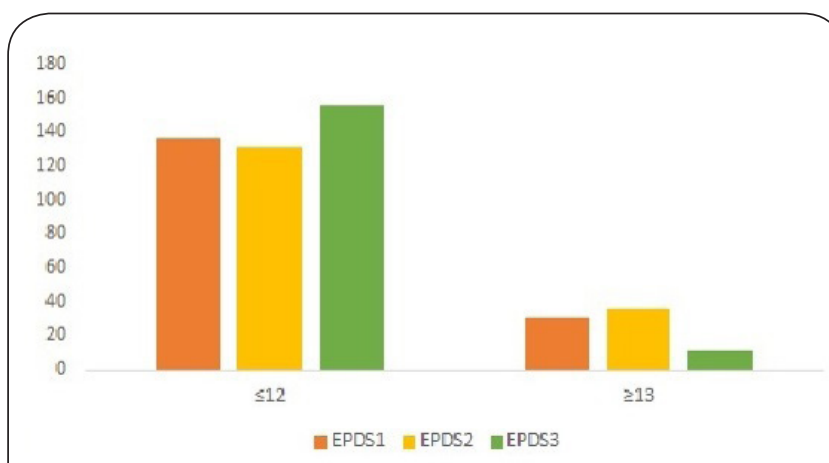

Figure 1. Comparison of EPDS scores across three stages.

$\mathrm{df}=1, \mathrm{p}=0.046)$ (Table 3 ).

Binary logistic regression analysis was employed to check the risk factors for antepartum depression. Hosmer and Lemeshow goodness of fit showed that the regression model employed was statistically sound for predictability $(p=0.65$ 
Bishnu et al. Research Journal of Women's Health 2017,

Table 2. Bivariate analysis ( $\chi 2$ test and Pearson chi-square test) to establish significance of associated risk factors with perinatal depression using third trimester EPDS score

\begin{tabular}{llll}
\hline Associated factors & $\begin{array}{l}\text { Pearson } \\
\text { Chi-square value }\end{array}$ & df & P-value \\
\hline Age & 4.786 & 1 & 0.029 \\
Parity & 4.258 & 1 & 0.039 \\
Occupational status & 5.282 & 1 & 0.022 \\
Education level & 4.215 & 1 & 0.040 \\
\hline
\end{tabular}

Table 3. Spearman's Correlation between EPDS score in third trimester, three days after delivery and one month postpartum.

\begin{tabular}{|c|c|c|c|c|c|}
\hline & & & $\begin{array}{l}\text { EPDS } \\
1\end{array}$ & $\begin{array}{l}\text { EPDS } \\
2\end{array}$ & $\begin{array}{l}\text { EPDS } \\
\mathbf{3}\end{array}$ \\
\hline \multirow{9}{*}{ Spearman's rho } & \multirow{3}{*}{ EPDS 1} & $\begin{array}{l}\text { Correlation } \\
\text { Coefficient }\end{array}$ & 1.000 & 0.012 & $0.184^{*}$ \\
\hline & & Sig. (2-tailed) & . & 0.879 & 0.018 \\
\hline & & $\mathrm{N}$ & 167 & 167 & 167 \\
\hline & \multirow{3}{*}{ EPDS 2} & $\begin{array}{l}\text { Correlation } \\
\text { Coefficient }\end{array}$ & 0.012 & 1.000 & $0.154^{*}$ \\
\hline & & Sig. (2-tailed) & 0.879 & . & 0.046 \\
\hline & & $\mathrm{N}$ & 167 & 167 & 167 \\
\hline & \multirow{3}{*}{ EPDS 3} & $\begin{array}{l}\text { Correlation } \\
\text { Coefficient }\end{array}$ & $0.184^{*}$ & $0.154^{*}$ & 1.000 \\
\hline & & Sig. (2-tailed) & 0.018 & 0.046 & . \\
\hline & & $\mathrm{N}$ & 167 & 167 & 167 \\
\hline
\end{tabular}

${ }^{\star}$ Correlation is significant at the 0.05 level (2-tailed).

and Predictability percentage $=82 \%)$. Binary logistic regression showed that parity (Wald $=4.754, \mathrm{p}=0.029, \mathrm{Cl}=0.059-0.860$ ), and occupation (Wald $=3.839, \mathrm{p}=0.050, \mathrm{Cl}=0.159-1.000$ ) were independent risk factors for antepartum depression (Table 4). Another regression analysis was done to find independent risk factors for postpartum depression. Hosmer and Lemeshow goodness of fit showed that the regression model employed was statistically sound for predictability $(p=0.365$ and Predictability percentage $=94 \%$ ). Mode of birth (Wald $=4.513, p=0.034$, $\mathrm{Cl}=0.35-0.874$ ), antepartum EPDS score (Wald $=3.877, \mathrm{p}=0.049$, $\mathrm{Cl}=1.006-14.316)$ and immediate postpartum EPDS score (Wald $=4.038, \mathrm{p}=0.044, \mathrm{Cl}=1.034-15.186$ ) were independent risk factors for postpartum depression (Table 5).

\section{Discussion}

In this study a total of 345 women were invited to participate in the study but only 167 women completed the questionnaire at all three point of time and were included in the analysis which is quite comparable to other reports of perinatal depression $[12,19,21]$.

With regards to the socio-demographic variables in our current study. Average age of women participating in this study was $28.31 \pm 5.03$ years is similar to $29 \pm 4$ years in study by Price SK. et al [22]. In our study we found that younger women are more likely to experience perinatal depressive symptoms $(p=0.029)$ which is similar to findings by Samantha Meltzer-Brody et al [23]. Several studies have shown that young adults are more prone to psychological break down [24] compared to adults when exposed to similar level of stress [25] so further studies has been done on children of antenatally depressed young women in a study by Raskin, M. et al [26].

Primiparitywas statistically significant factor for PND $(p=0.039)$ in current studysimilar to previous studies $[27,28]$. With experience of previous delivery there is development of psychological coping with changes that occurs during pregnancy. So it seems obvious to have more anxious patients among primiparous women and higher chance of PND in same group of individuals.

Previous history of abortion had been proven to predis-

Table 4. Binary Logistic Regression models examining associated factors for perinatal depression among Chinese women during third trimester of pregnancy $(\mathrm{N}=167)$.

\begin{tabular}{llllllll}
\hline Associated factors & B & S.E. & Wald & df & P-value & $\operatorname{Exp}(B)$ & C.I. ${ }_{95 \%}$ \\
\hline Age & -0.740 & 0.426 & 3.022 & 1 & 0.082 & 0.477 & $0.207-1.099$ \\
Parity & -1.492 & 0.684 & 4.754 & 1 & $0.029^{*}$ & 0.225 & $0.059-0.860$ \\
Education level & -1.441 & 0.802 & 3.225 & 1 & 0.073 & 0.237 & $0.049-1.141$ \\
Occupational status & -0.919 & 0.469 & 3.839 & 1 & $0.050^{*}$ & 0.399 & $0.159-1.000$ \\
\hline
\end{tabular}

${ }^{*} \mathrm{p}<0.05$ is considered significant

Table 5. Binary Logistic Regression models examining significance of EPDS 3 with EPDS 1, EPDS 2 and Mode of birth.

\begin{tabular}{lcccclll}
\hline & B & S.E. & Wald & df & P-value & $\operatorname{Exp(B)}$ & C.I. $_{95 \%}$ \\
\hline EPDS 1 & 1.334 & 0.677 & 3.877 & 1 & $0.049^{*}$ & 3.795 & $1.006-14.316$ \\
EPDS 2 & 1.377 & 0.685 & 4.038 & 1 & $0.044^{*}$ & 3.963 & $1.034-15.186$ \\
Mode of birth & -1.748 & 0.823 & 4.513 & 1 & $0.034^{*}$ & 0.174 & $0.035-0.874$ \\
\hline
\end{tabular}

${ }^{*} \mathrm{p}<0.05$ is considered significant 
pose PND in several studies but surprisingly in current study we found higher percentage of participants without abortion history (19.6\%) had PND in comparison with previous history of abortion (16.9\%). Though, this rise was statically insignificant it can be assumed that the previous abortion didn't impact PND as majority of them were planned abortion for unplanned pregnancy or intentional female feticide [29]. Though strict laws are being incorporated in China but still sex-determining abortion are rampant in rural China and same in case here in our study base.

Mothers conceiving by artificial reproductive technique are more likely to get depression [30]. Mode of conception is found to be insignificant with PND statistically but percentagewise women with artificial reproductive technique (25\%) were more prone to depression compared to conception by natural process (17.8\%). We had limited number of participant with artificial reproductive technique so we could not definitely conclude that those women conceiving by artificial reproductive technique predisposes to PND.

Mode of birth was significantly associated with EPDS score. Chi square test after Yate's correction showed that women with normal delivery had higher score (Normal delivery $=38 \%$ and Cesarean delivery $=16 \%$ ) at 0.008 level of significance. This may be due to the high level of pain and stress perceived by women during normal delivery compared to cesarean delivery with adequate epidural analgesia [31]. However, in study by Hannah P. et al showed that delivery by cesarean method has higher EPDS score [32].

Demographic factor having impact on EPDS 1 score didn't exhibit statically significant impact upon EPDS 2 and EPDS 3 but EPDS 3 score was statically co-relatable with EPDS 1 and EPDS 2 score. EPDS 1 had stronger correlation with EPDS $3\left(x^{2}=3.977, d f=1, p=0.018\right)$ compared to correlation between EPDS 2 and EPDS $3\left(x^{2}=3.977, d f=1, p=0.046\right)$ so, we can assumed that the demographic variables impacting EPDS 1 have impact on EPDS 2 and/or EPDS 3 as previous depressive stage during antepartum tends to continue postpartum. If the screening had been done only after the delivery, existing risk for depression might have gone unrecognized.

Bivariate regression analysis showed that parity $(\mathrm{p}=0.029)$ and occupation (0.050) were independent risk factors for development of antepartum depression. Several previous studies have established parity and occupation as independent risk factors for PND $[33,34]$. Based on this study it can be suggested that expecting mothers should be encouraged to get engaged in some activities if they are having ample free time. Nulliparous women require more family and social care and support during their pregnancy. Clinicians attending woman with similar risk factors should be encouraged for detailed screening and counseling to prevent PND in such patients.

Bivariate regression analysis further showed that EPDS 1 $(p=0.049)$, EPDS $2(p=0.044)$ and mode of birth $(p=0.034)$ are independent risk factors for postpartum depression.

Current study findings clearly points that antenatal screen- ing for depression helps to predict development of postpartum depression. Based on these findings one can assume that prenatal depression tends to continue in postnatal period. Clinician attending expecting mother must be encouraged to carry out early assessment of psychological status of expecting mother and when one find high risk factor and developing depression prenatally patient should be encouraged for psychiatric consultation to avoid PND.

\section{Conclusions}

1) Higher EPDS score prenatally tends to persist postnatal indicating chances of developing postpartum depression in susceptible individuals.

2) Early screening prenatally can guide clinician for active psychological support to susceptible cases thereby minimizing probabilityof postpartum depressions.

\section{Additional file

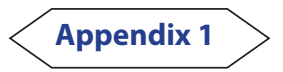

\section{Competing interests}

The authors declare that they have no competing interests.

\section{Authors' contributions}

\begin{tabular}{|l|c|c|c|c|c|c|c|c|}
\hline Authors' contributions & PB & TLB & KKS & PJ & SSQ & PYL & HJ & XTR \\
\hline $\begin{array}{l}\text { Research concept and } \\
\text { design }\end{array}$ & $\checkmark$ & $\checkmark$ & -- & -- & -- & -- & -- & -- \\
\hline $\begin{array}{l}\text { Collection and/or assembly } \\
\text { of data }\end{array}$ & $\checkmark$ & -- & -- & -- & $\checkmark$ & $\checkmark$ & $\checkmark$ & $\checkmark$ \\
\hline $\begin{array}{l}\text { Data analysis and } \\
\text { interpretation }\end{array}$ & $\checkmark$ & -- & $\checkmark$ & $\checkmark$ & -- & -- & -- & -- \\
\hline Writing the article & $\checkmark$ & -- & -- & -- & -- & -- & -- & -- \\
\hline $\begin{array}{l}\text { Critical revision of the } \\
\text { article }\end{array}$ & $\checkmark$ & -- & -- & $\checkmark$ & -- & -- & -- & -- \\
\hline Final approval of article & $\checkmark$ & -- & -- & -- & -- & -- & -- & -- \\
\hline Statistical analysis & $\checkmark$ & -- & $\checkmark$ & -- & -- & -- & -- & -- \\
\hline
\end{tabular}

\section{Acknowledgement}

Bishnu Palikhe would like to thank tutor Prof. Tong Li Bo for valuable opinion on this manuscript. I would like to thank Kalu Singh Khatri for valuable opinion in statistical analysis in this manuscript.

\section{Publication history}

Editor: George Perry, The University of Texas at San Antonio, USA. Received: 27-Nov-2016 Final Revised: 10-Jan-2017

Accepted: 03-Feb-2017 Published: 21-Feb-2017

\section{References}

1. Weissman MM and Olfson M. Depression in women: implications for health care research. Science. 1995; 269:799-801. | Article I PubMed

2. Kaida A, Matthews LT, Ashaba S, Tsai AC, Kanters S, Robak M, Psaros C, Kabakyenga J, Boum Y, Haberer JE, Martin JN, Hunt PW and Bangsberg DR. Depression during pregnancy and the postpartum among HIVinfected women on antiretroviral therapy in Uganda. J Acquir Immune Defic Syndr. 2014; 67 Suppl 4:S179-87. | Article | PubMed Abstract | PubMed FullText

3. WHO. Programmes and projects $>$ World health report $>$ The world health report 2001. Mental Health: New Understanding, New Hope. 
Bishnu et al. Research Journal of Women's Health 2017,

\section{1. | Pdf}

4. Fisher J, Cabral de Mello M, Patel V, Rahman A, Tran T, Holton S and Holmes W. Prevalence and determinants of common perinatal mental disorders in women in low- and lower-middle-income countries: a systematic review. Bull World Health Organ. 2012; 90:139G-149G. | Article | PubMed Abstract | PubMed FullText

5. Lau Y, Wong DF and Chan KS. The utility of screening for perinatal depression in the second trimester among Chinese: a three-wave prospective longitudinal study. Arch Womens Ment Health. 2010; 13:153-64. | Article | PubMed Abstract | PubMed FullText

6. Gynecologists, A.C.o.O.a. Screening for Perinatal Depression. 2015. | Article

7. Ontario R.N.A.o. Interventions for postpartum depression. Registered Nurses Association of Ontario, Canada. 2005. | Article

8. Guedeney $\mathrm{N}$ and Fermanian J. Validation study of the French version of the Edinburgh Postnatal Depression Scale (EPDS): new results about use and psychometric properties. Eur Psychiatry. 1998; 13:83-9. | Article | PubMed

9. Karacam Z and Kitis Y. [The Postpartum Depression Screening Scale: its reliability and validity for the Turkish population]. Turk Psikiyatri Derg. 2008; 19:187-96. | PubMed

10. Richter P, Werner J, Heerlein A, Kraus A and Sauer H. On the validity of the Beck Depression Inventory. A review. Psychopathology. 1998; 31:160-8. | PubMed

11. Bennett IM, Coco A, Coyne JC, Mitchell AJ, Nicholson J, Johnson E, Horst $M$ and Ratcliffe $S$. Efficiency of a two-item pre-screen to reduce the burden of depression screening in pregnancy and postpartum: an IMPLICIT network study. J Am Board Fam Med. 2008; 21:317-25. I Article | PubMed Abstract | PubMed FullText

12. Menard S. Longitudinal Research. SAGE Publications. 2002. | Book

13. Department of Health G.o.W.A. Edinburgh Postnatal depression Scale (EPDS): Translated versions- validated. Perth, Western Australia: State Perinatal Mental Health Reference Group. 2006; 31-32. I Pdf

14. Cox JL, Holden JM and Sagovsky R. Detection of postnatal depression. Development of the 10-item Edinburgh Postnatal Depression Scale. $\mathrm{Br} J$ Psychiatry. 1987; 150:782-6. | Article | PubMed

15. Howard LM, Molyneaux E, Dennis CL, Rochat T, Stein A and Milgrom J. Non-psychotic mental disorders in the perinatal period. Lancet. 2014; 384:1775-88. | Article | PubMed

16. Buist A, Bilszta J, Milgrom J, Barnett B, Hayes B and Austin MP. Health professional's knowledge and awareness of perinatal depression: results of a national survey. Women Birth. 2006; 19:11-6. | Article | PubMed

17. Sit DK and Wisner KL. Identification of postpartum depression. Clin Obstet Gynecol. 2009; 52:456-68. | Article | PubMed Abstract | PubMed FullText

18. Su KP, Chiu TH, Huang CL, Ho M, Lee CC, Wu PL, Lin CY, Liau CH, Liao $\mathrm{CC}$, Chiu WC and Pariante CM. Different cutoff points for different trimesters? The use of Edinburgh Postnatal Depression Scale and Beck Depression Inventory to screen for depression in pregnant Taiwanese women. Gen Hosp Psychiatry. 2007; 29:436-41. | Article | PubMed

19. Kumwar D, Corey EK, Sharma P and Risal A. Screening for Postpartum Depression and Associated Factors among Women who Deliver at a University Hospital, Nepal. Kathmandu Univ Med J (KUMJ). 2015; 13:448. | Article | PubMed

20. Zeng J, Zou G, Song $X$ and Ling L. Contraceptive practices and induced abortions status among internal migrant women in Guangzhou, China: a cross-sectional study. BMC Public Health. 2015; 15:552. | Article | PubMed Abstract | PubMed FullText

21. Michael W and O'hara A.M.S. Rates and Risk of Postpartum Depression-a Meta-Analysis. Research Gate. 2009; 8:37-54.

22. Price SK and Masho SW. What does it mean when we screen? A closer examination of perinatal depression and psychosocial risk screening within one MCH home visiting program. Matern Child Health J. 2014; 18:765-71. | Article | PubMed Abstract | PubMed FullText

23. Meltzer-Brody S. New insights into perinatal depression: pathogenesis and treatment during pregnancy and postpartum. Dialogues Clin Neurosci. 2011; 13:89-100. | Article | PubMed Abstract | PubMed FullText

24. Stein $\mathrm{K}$ and Fazel M. Depression in young people often goes undetected. Practitioner. 2015; 259:17-22, 2-3. | Pdf | PubMed

25. Gautam S, Nijhawan M and Gehlot PS. Post partum psychiatric syndromes-an analysis of $\mathbf{1 0 0}$ consecutive cases. Indian J Psychiatry. 1982; 24:383-6. | PubMed Abstract | PubMed FullText

26. Raskin M, Easterbrooks MA, Lamoreau RS, Kotake C and Goldberg J. Depression Trajectories of Antenatally Depressed and Nondepressed Young Mothers: Implications for Child Socioemotional Development. Womens Health Issues. 2016; 26:344-50. | Article | PubMed

27. Henderson J and Redshaw M. Worries About Labor and Birth: A Population-Based Study of Outcomes for Young Primiparous Women. Birth. 2016; 43:151-8. | Article | PubMed

28. Rai S, Pathak A and Sharma I. Postpartum psychiatric disorders: Early diagnosis and management. Indian J Psychiatry. 2015; 57:S216-21. | Article | PubMed Abstract | PubMed FullText

29. Qadir F, Khan MM, Medhin G and Prince M. Male gender preference, female gender disadvantage as risk factors for psychological morbidity in Pakistani women of childbearing age - a life course perspective. $B M C$ Public Health. 2011; 11:745. | Article | PubMed Abstract | PubMed FullText

30. van Dongen AJ, Nelen WL, IntHout J, Kremer JA and Verhaak CM. e-Therapy to reduce emotional distress in women undergoing assisted reproductive technology (ART): a feasibility randomized controlled trial. Hum Reprod. 2016; 31:1046-57. | Article | PubMed

31. Eisenach JC, Pan PH, Smiley R, Lavand'homme P, Landau R and Houle TT. Severity of acute pain after childbirth, but not type of delivery, predicts persistent pain and postpartum depression. Pain. 2008; 140:87-94. | Article | PubMed Abstract | PubMed FullText

32. Hannah $P$, Adams D, Lee A, Glover $V$ and Sandler M. Links between early post-partum mood and post-natal depression. Br J Psychiatry. 1992; 160:777-80. | Article | PubMed

33. Sagayadevan V, Lee SP, Abdin E, Vaingankar J, Chen H, Chong SA and Subramaniam M. Retrospective observation of mental disorders during postpartum period: Results from the Singapore mental health study. BMC Womens Health. 2015; 15:119. | Article | PubMed Abstract | PubMed FullText

34. Raisanen S, Lehto SM, Nielsen HS, Gissler M, Kramer MR and Heinonen $S$. Risk factors for and perinatal outcomes of major depression during pregnancy: a population-based analysis during 2002-2010 in Finland. BMJ Open. 2014; 4:e004883. | Article | PubMed Abstract | PubMed FullText

\section{Citation:}

Bishnu P, Bo TL, Singh KK, Jewan P, Qun SS, Lan PY, Jian $\mathrm{H}$ and Rong XT. A hospital based prospective survey of perinatal depression in Chinese women of Jiamusi city. Res J Womens Health. 2017; 4:2. http://dx.doi.org/10.7243/2054-9865-4-2 